IX. REPORTS, COMMENTS AND REMARKS 
BUSINESS MEETING

\title{
Recommendations/Resolutions Adopted by the Twelfth International Radiocarbon Conference
}

\author{
WILLEM G MOOK
}

Department of Physics, University of Groningen, The Netherlands

The following recommendations/resolutions were adopted:

- Conventional ${ }^{14} \mathrm{C}$ ages - based on $\mathrm{T}_{1 / 2}=5568$ years and NBS oxalic acid activity - are to be reported in years BP where 0 BP is the year 1950 .

- Dendrochronologically calibrated ages are to be reported as cal AD or cal $\mathrm{BC}$, or, if required, cal $\mathrm{BP}$.

- Historical - non ${ }^{14} \mathrm{C}$-ages are generally given in AD or $\mathrm{BC}$. The use of $\mathrm{AD} / \mathrm{BC}$ in connection with ${ }^{14} \mathrm{C}$ ages by archaeologists is discouraged. It should be noted, however, that in the past, extensive use has been made of $\mathrm{AD} / \mathrm{BC}$ dates obtained by subtracting 1950 years from conventional ages $\mathrm{BP}$.

- Calibration curves for ${ }^{14} \mathrm{C}$ should contain real time on the horizontal axis (progressing time to the right) and conventional ${ }^{14} \mathrm{C}$ age on the vertical axis (increasing age in the upward direction). The abscissa scale thus indicates cal $\mathrm{BC}$ and $\mathrm{cal} \mathrm{AD}$ (if required cal $\mathrm{BP}$ ), the ordinate scale indicates years BP.

- The standard deviation of the calibration curve $\left(\sigma_{c}\right)$ is to be incorporated in the standard deviation of the ${ }^{14} \mathrm{C}$ measurement $(\sigma)$ by applying $\sqrt{\sigma^{2}+\sigma_{\mathrm{c}}^{2}}$ before the calibration conversion is carried out.

- The calibration curves by Stuiver and Pearson for the period $500 \mathrm{BC}$ to the present, and by Pearson and Stuiver for the period 2500 BC to $500 \mathrm{BC}$ as published in the special volume of the Proceedings of the XIIth International Radiocarbon Conference, Trondheim, 1985 (Radiocarbon, v 28, No. 2B) have sufficiently been double-checked to serve as the officially recommended calibration curves for the period mentioned.

- Calibration graphs used should contain a reference to the curve's author(s) in the upper righthand corner (eg, on computer printouts). Computer printouts should identify the curve's authors for each calibrated date.

$-{ }^{14} \mathrm{C}$ ages from Southern Hemisphere samples should be diminished by 30 years before applying existing calibration curves.

- And, as a matter for deliberation, the SI system symbol for year is "a". 